\title{
Experimental and numerical study on the screw connection strength of bamboo-oriented strand board compared with wood-oriented strand board
}

\author{
Kaiting Zhang ${ }^{\dagger}$, Fuli Wang ${ }^{\dagger}$, Runmin Xu ${ }^{\dagger}$, Xinhui Fan ${ }^{\dagger}$, Bin Yan, Chuangye Li, Shengquan Liu*, Yong Guo and \\ Yuxia Chen ${ }^{*}$
}

\begin{abstract}
The utilization of resourceful bamboo can alleviate the wood shortage problem. Bamboo-oriented strand board (BOSB) with the highest utilization of bamboo ratio and excellent mechanical properties was considered as a good engineering and furniture material. The strength of joints affects the safety of BOSB structure. This study aims to investigate the effect of screw spacing on the tensile and compressive stiffness and strength of corner joints from BOSB by experimental method combined with finite element method (FEM) compared with wood-oriented strand board (WOSB). The results showed that (1) the strength and stiffness of the corner joint was significantly affected by the screw spacing, and it affected the compressive strength and stiffness of WOSB more significantly; (2) the bending moment and stiffness coefficient of BOSB compressed joint decreased with the increase of spacing, while that of tensile joint increased first and then decreased, and it reached the maximum value, when the spacing was $48 \mathrm{~mm}$; (3) compared with WOSB joint, BOSB joint had higher strength and stiffness, and the failure of the joint was due to the yielding of self-drilling screws. This was also verified by numerical analysis results; (4) the bending moment of BOSB joints was about 2.5 times that of WOSB joints, while the difference between stiffness coefficient was small; (5) the elastic deformations resulted from experimental tests and FEM are similar. It was shown that when the screw spacing is $48 \mathrm{~mm}$, the Von Mises stresses on the BOSB joint were smaller, and the bending strength and stiffness were larger, which was the most suitable screw spacing.
\end{abstract}

Keywords: Screw spacing, Bamboo-oriented strand board, Corner joint, Finite element method, Strength and stiffness

\section{Introduction}

China is one of the countries with the richest bamboo resources and is known as the "Bamboo Kingdom" [1]. Moreover, bamboo utilization ranks first in the world in terms of product varieties, scale, and output [1-4]. In

\footnotetext{
*Correspondence: liusq@ahau.edu.cn; fly828828@163.com; sheherose@163.com ${ }^{\dagger}$ Kaiting Zhang, Fuli Wang, Runmin Xu and Xinhui Fan contributed equally to this work

College of Forest and Garden, Anhui Agricultural University, Hefei 230036, China
}

recent years, the development of bamboo-oriented strand board (BOSB) made of bamboo shavings [5-7] improves the utilization of bamboo and makes it possible to use small diameter bamboo and poor-quality materials [8]. Moreover, BOSB has the advantages of more excellent mechanical properties [1] and better dimensional stability $[9,10]$ compared with wood-oriented strand board (WOSB), which is considered as a good engineering and furniture material $[11,12]$. The strength of furniture is not only affected by the mechanical properties of materials, but also depends on the stiffness and stability of joints 
[13]. The joints in furniture are the weakest elements in terms of their strength and stiffness [14]. Therefore, many studies focus on the bending moment capacity and stiffness of joints [15]. So far, the mechanical properties of wood composite joints have been studied comprehensively, such as PB (particleboard), MDF (medium-density fiberboard), HDF (high-density fiberboard), WOSB as well as new adhesives and connectors. However, there are few researches on the strength of BOSB jointed.

BOSB with high hardness is more suitable for thread connections to obtain greater mechanical strength, compared with non-threaded connections [16-18]. Compared with the two-in-one, three-in-one (with embedded nut), wood screw, and other threaded connectors, the thread end of self-drilling screws is narrower, the thread spacing is smaller, and the thread has a greater effect on the shear and extrusion deformation of bamboo fiber, so its connection strength is greater than other threaded connectors [19]. Self-drilling screws are widely used in the design of contemporary furniture, especially wooden and non-disassemble furniture [20]. Screws can be used as an auxiliary for joining connectors and materials, and can also be directly used for fixing corner joints, such as the joint of back plates and side plates, feet and boxes, and laminate plates and side plates. In 2018, Guo et al. found that the screw withdrawal resistance of BOSB is much higher than conventional particleboard in all directions [21]. The durability of BOSB fixed with self-drilling screws is greater than that of WOSB and glued laminated bamboo [17]. However, the performance of BOSB corner joints fixed by screws has not been studied.

Moreover, the screw spacing affects the strength of joints in furniture [22-25]. Improper installation spacing of screws would affect both the efficiency and cost of production and the stability and safety of furniture. However, there is no research about the influence of installation spacing on the connection strength of BOSB. A review of the literature shows that the strength of most furniture corner joint is obtained by experimental method $[13,26]$, which is destructive and non-repeatable, and only the failure strength and pattern of joints can be obtained. Therefore, knowledge of the stress distribution of joint is limited, which is not conducive to the optimization of furniture structure [27]. With the development of finite element software functions, the finite element analysis method is applied to the structural design of furniture gradually $[2,28,29]$. In the process of furniture design, FEM (finite element analysis) can be used as a fast and effective simulation method. Mechanical analysis can be done by the simulations of complex materials and models under different loads [2]. And the simulations are repeatable.
Therefore, the experimental and FEM analysis are used to investigate the effect of screw spacing on corner joint strength and stiffness of BOSB and WOSB to optimize screw connection. The specific objectives of this study are to (1) investigate the effect of screw spacing on the strength and stiffness of BOSB and WOSB joint by experimental and FEM method; (2) verify the accuracy of the FEM compared with the experimental results; (3) determine the optimal self-drilling screws installation spacing of BOSB and WOSB joint.

\section{Materials and methods}

\section{Properties of selected materials}

Samples were BOSB and WOSB, which were considered to be isotropic parallel to their wide surfaces. The density and moisture content were measured according to the ASTM D4442-92 [30] and ASTM D2395-93 [31], respectively. The Young's modulus and tensile strength $\left(\sigma_{\mathrm{T}}\right)$ were measured by uniaxial tension test [32-34]. Poisson's ratio was tested with strain gauge method according to ASTM D3039 [35]. Conventional yield point $R_{0.2}$ was determined using the uniaxial tensile tests method. Based on the stress-strain diagram, the yield strength $R_{0.2}(\mathrm{MPa})$ (Fig. 1) represents the stress value that produces $0.2 \%$ residual deformation [29]. The average test values of three square plate specimens can be obtained by repeated tests.

Self-drilling screw is stainless steel, with nominal diameter $(D)$ of $3.97 \mathrm{~mm}$, inner rod diameter $(d)$ of $2.76 \mathrm{~mm}$, length $(L)$ of $39.73 \mathrm{~mm}$, thread length $\left(L_{/}\right.$ Thread) of $31.5 \mathrm{~mm}$, screw pitch $(P)$ of $1.40 \mathrm{~mm}$ (shown in Fig. 2) and the yield strength and modulus of elasticity were measured according to standard LY/T 32192020 [36].

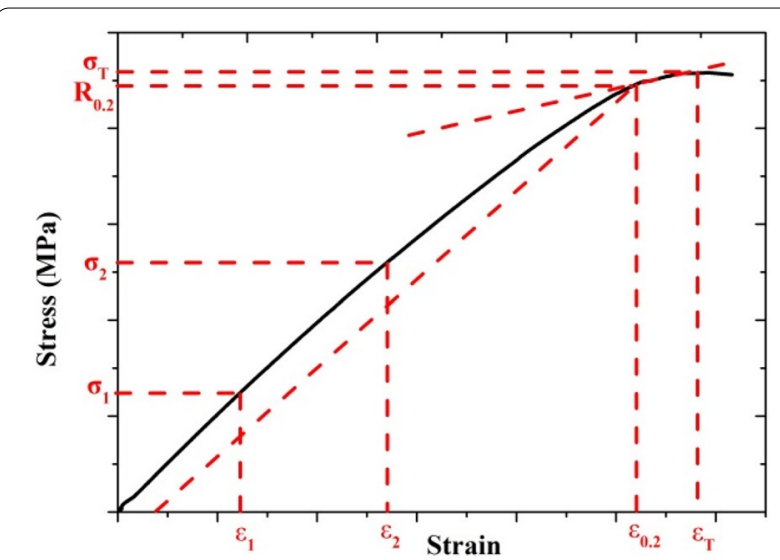

Fig. 1 Diagram used to determine conventional proportionality limit and yield point 


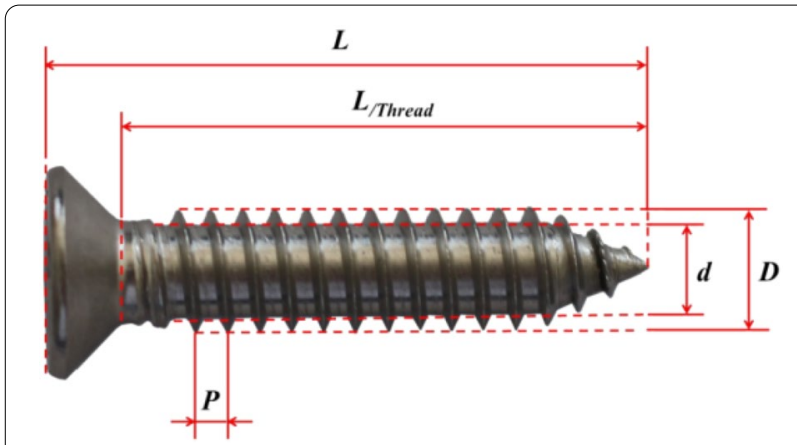

Fig. 2 Dimensions of self-drilling screw

\section{Preparation of joints}

The self-drilling screws were bought from a local commercial supplier (Hefei, China). The dimensions of BOSB were $150 \times 100 \times 15 \mathrm{~mm}$ and $135 \times 100 \times 15 \mathrm{~mm}$, and the dimensions of WOSB were $150 \times 100 \times 18 \mathrm{~mm}$ and $132 \times 100 \times 18 \mathrm{~mm}$. The screw spacing $(\mathrm{S})$ was $16,32,48$, 64 , and $80 \mathrm{~mm}$, respectively, symmetrically distributed, and fixed in the middle line of the thickness direction of the plates (shown in Fig. 3). Self-drilling screws were installed with a guide hole of $3.4 \mathrm{~mm}$, penetrating one plate then inserting into the other one. 10 repetitions of each joint are prepared, and there were 100 specimens in total.

\section{Strength testing}

Joint mechanical properties were determined in compression and tension tests (Fig. 4). Tests were performed using a mechanical testing machine (model: WDW-100E, Jinan Chenda Testing Machine Manufacture Co., Ltd., Jinan, China). Crosshead speed was $10 \mathrm{~mm} / \mathrm{min}$. The experimental tests directly provided dependence between force $P$ and

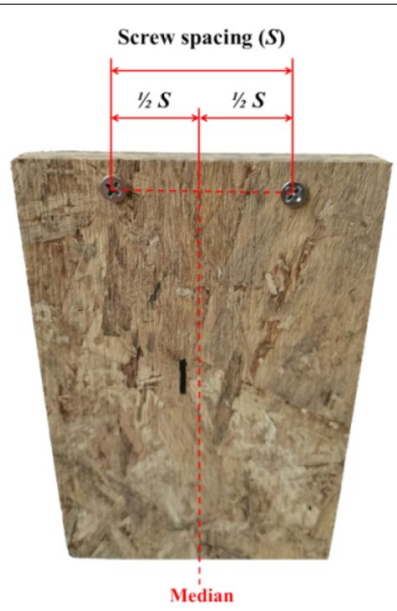

Fig. 3 Illustration of screw installation

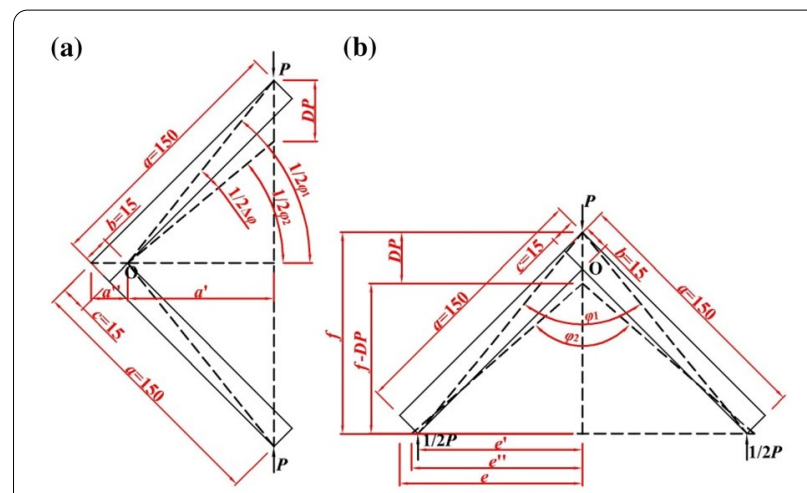

Fig. 4 Method of joint analysis: a compression, b tension

displacement $D P$. The strength of the joint was calculated as:

$$
\begin{aligned}
& M_{\mathrm{C}}=P_{\max } a^{\prime}, \\
& M_{\mathrm{T}}=0.5 P_{\max } e^{\prime},
\end{aligned}
$$

where $M_{\mathrm{C}}$ was the bending moment resistance of the joint under compression loading $(\mathrm{N} \mathrm{m}), M_{\mathrm{T}}$ was the bending moment resistance of the joint under tension loading $(\mathrm{N} \mathrm{m}), P_{\max }$ was the maximum load in each test sample $(\mathrm{N}), a^{\prime}$ and $e$ ' were the moment arm in compression and tension, respectively $(\mathrm{m})$.

For selected load diagrams, the stiffness coefficient of joint $K(\mathrm{~N} \cdot \mathrm{m} / \mathrm{rad})$ was presented as the quotient of the bending moment for joint posts or rails $0.4 M_{\mathrm{C}}$ or $0.4 M_{\mathrm{T}}$ and rotation angle $\Delta \phi$ between the joint arms. This angle was determined based on the changes in joint geometry $[15,29,34]$.The coefficient of stiffness coefficient $K$ subjected to compression (Fig. 4a) for the range of linear elasticity of joint was described by the equation [15]:

$$
K_{\mathrm{C}}=\frac{0.4 M_{\mathrm{C}}}{\Delta \varphi}
$$

where:

$$
\begin{aligned}
& \Delta \varphi=\frac{\pi}{90}\left(\varphi_{1}-\varphi_{2}\right), \\
& a^{\prime}=\frac{\sqrt{2}}{2} a-a^{\prime \prime} \\
& a^{\prime \prime}=\sqrt{b^{2}-c^{2}}
\end{aligned}
$$




$$
\begin{aligned}
& \varphi_{1}=\operatorname{atg}\left(\frac{\frac{\sqrt{2}}{2} a}{a^{\prime}}\right), \\
& \varphi_{2}=\operatorname{asin}\left(\frac{\frac{\sqrt{2}}{2} a-D P_{0.4 P_{\max }}}{\sqrt{c^{2}+(a-b)^{2}}}\right), \\
& D P_{0.4 P_{\text {max }}}=0.4 \times D P_{\text {max }} .
\end{aligned}
$$

The stiffness of joints subjected to tension (Fig. 3b) for the range of linear elasticity was calculated from the following equations:

$$
\begin{aligned}
& K_{\mathrm{T}}=\frac{0.4 M_{\mathrm{T}}}{\Delta \varphi}, \\
& \Delta \varphi=\frac{\pi}{90}\left(\varphi_{2}-\varphi_{1}\right), \\
& e^{\prime}=\frac{\sqrt{2}}{2}(a-b), \\
& a^{\prime \prime}=\sqrt{b^{2}-c^{2}}, \\
& 0.5 \varphi_{1}=\operatorname{atg}\left(\frac{e^{\prime}}{f}\right), \\
& 0.5 \varphi_{2}=\operatorname{atg}\left(\frac{e^{\prime \prime}}{f-D P_{0.4 P_{\max }}}\right), \\
& f=e+\frac{\sqrt{2}}{2} b, \\
& e^{\prime \prime}=\sqrt{e^{\prime 2}+f^{2}-\left(f-D P_{0.4 P_{\max }}\right)^{2},} \\
& D P_{0.4 P_{\max }}=0.4 \times D P_{\max } .
\end{aligned}
$$

\section{The numerical model of joints}

Modeling and numerical simulations were performed using the Siemens NX 12.0 program and Ansys workbench 17.0 software, respectively. Geometry, loading and boundary conditions of the model were based on Fig. 3. The thread features of screw were ignored in Numerical simulation. Between the hole in the board and screw, the bonded interaction was applied. The contact property between boards was specified with a friction coefficient of 0.1 . The elements sizes of board and screw were approximately $3 \mathrm{~mm}$ and $5 \mathrm{~mm}$, while for contact parts, the sizes of elements were approximate $3 \mathrm{~mm}$ to make the model more accurate. In general, 10-node modified quadratic tetrahedron element C3D10M was used (about 48,240 elements and 74,640 nodes per model). In addition, geometric nonlinearity is considered to represent the large deformation of the structure.

\section{Results and analysis}

Properties of materials

As seen in Table 1, the mean density of BOSB was $806.61 \mathrm{~kg} / \mathrm{m}^{3}$, which was about 1.4 times that of WOSB. The Young's modulus and tensile strength of BOSB were both about three times that of WOSB. The data in Table 1 would be used for the finite element analysis.

\section{Strength of joints}

It could be observed in Fig. $5 \mathrm{a}$, b that curves for BOSB joint were smooth with no rapid changes after the maximum forces, but the curve of WOSB joint dropped rapidly after reaching the maximum force. This mean that the BOSB joints fixed by self-drilling screw had good durability and the strength of the joints did not decrease rapidly after reaching ultimate load, which could ensure

\begin{tabular}{|c|c|c|c|c|c|c|}
\hline Material & $\begin{array}{l}\text { Thickness/ } \\
\text { diameter (mm) }\end{array}$ & Density $\left(\mathrm{kg} / \mathrm{m}^{3}\right)$ & $\begin{array}{l}\text { Young's modulus } \\
\text { (MPa) }\end{array}$ & $\begin{array}{l}\text { Tensile strength } \\
\text { (MPa) }\end{array}$ & Poisson's ratio & Yield point (MPa) \\
\hline BOSB & 15 & 806.61 & 6770.86 & 32.09 & 0.33 & 27.85 \\
\hline WOSB & 18 & 569.20 & 2096.15 & 9.10 & 0.32 & 7.98 \\
\hline Screw & 4 & & $36,521.08$ & & 0.30 & 646.44 \\
\hline
\end{tabular}
the safety of the joint. Numerical calculations for the examined joints are also presented in Fig. 5, and the regularity of the loading curves obtained from the FEM was similar to test curves.

Seen from Fig. 5, the displacement-force curve could be approximately categorized into two stages. In the first stage, the correlation between force and displacement was almost linear, which confirmed the Hook's law [25]. The angle of curves with the horizontal axis represented the stiffness of joint [33]. In the case of compression, the

Table 1 Physical and mechanical properties of board and screw 

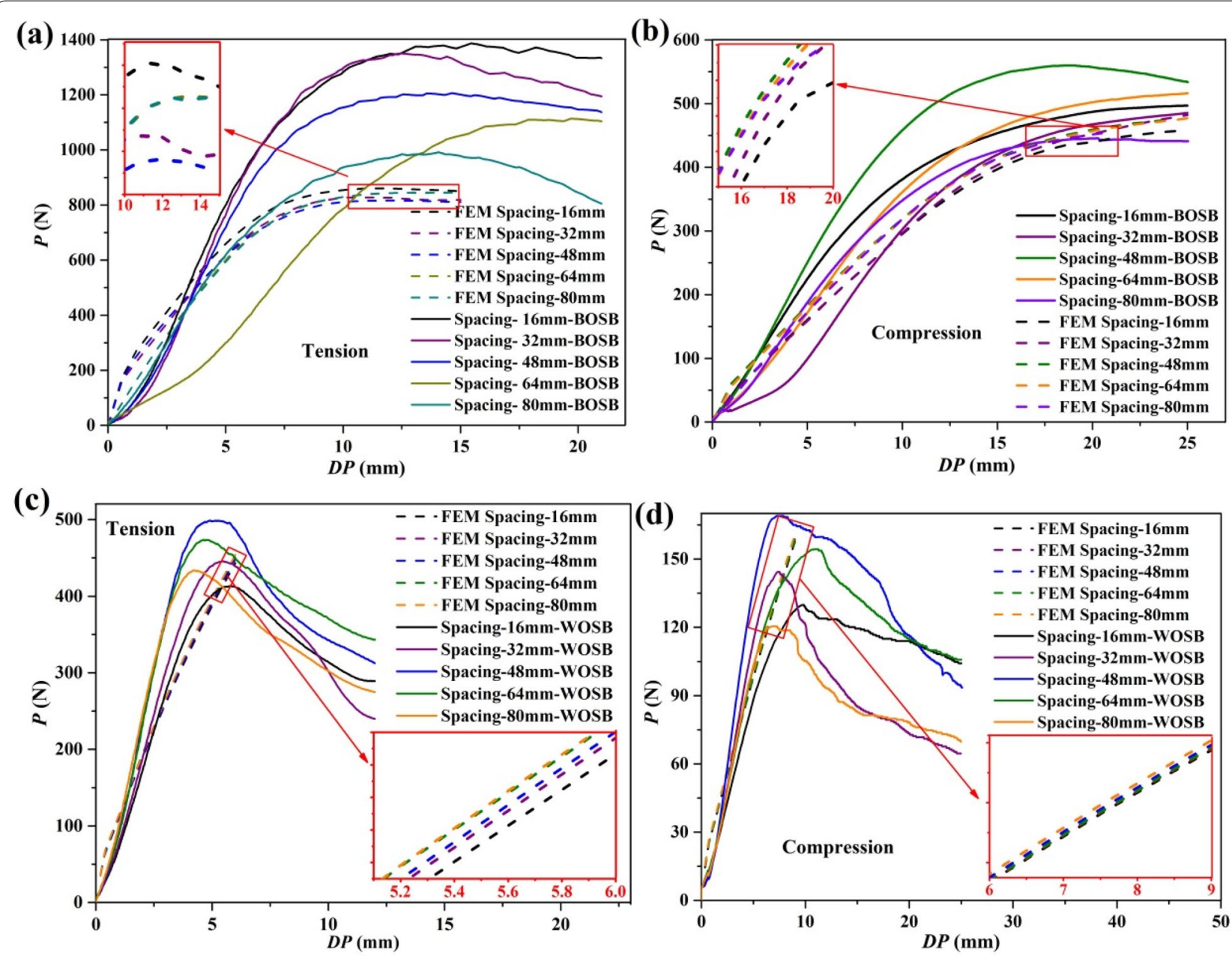

Fig. $\mathbf{5}$ The displacement-force curve of joints: $\mathbf{a}$, $\mathbf{b}$ was tension and compression test curves of BOSB joint, $\mathbf{c}$, $\mathbf{d}$ was tension and compression curves of WOSB joint

angle of BOSB joints with screws spacing of $48 \mathrm{~mm}$ was the largest, which represented the maximum strength and stiffness of this joint. Also, the angle was the largest for the WOSB joint with screw spacing of $48 \mathrm{~mm}$. Moreover, the angles of BOSB joints with the spacing of 32,64 and $80 \mathrm{~mm}$ were almost the same, but the maximum force was obviously different, which indicated that the three joints had similar stiffness, but the strength was different. Among BOSB joints, the compression ultimate force with screw spacing of $64 \mathrm{~mm}$ was largest, $505 \mathrm{~N}$, and that of $80 \mathrm{~mm}$ was smallest $(456 \mathrm{~N})$. In the tensile test results, the BOSB joint with screw spacing of $16 \mathrm{~mm}$ had the maximum ultimate force $(1460 \mathrm{~N})$, which was $36 \%$ higher than that of the BOSB joint with the spacing of $80 \mathrm{~mm}(1071 \mathrm{~N})$. For the WOSB joints with screw spacing of $48 \mathrm{~mm}, 64 \mathrm{~mm}$ and $80 \mathrm{~mm}$ had the same angle between the curve and the horizontal coordinate, which indicated that the stiffness was similar, while, the WOSB joint with screw spacing of $48 \mathrm{~mm}$ had the highest ultimate force $(501 \mathrm{~N})$, followed by that of $64 \mathrm{~mm}(477 \mathrm{~N})$.

Overall, the strength of joints subjected to tension was almost twofold greater than compressed joints, and the deflection of joints in the tension test was approximately twofold smaller than compressed samples. At the same time, the maximum force of BOSB was about 3 times of WOSB.

Typical damages of arms are illustrated in Fig. 6 caused by joint compression or tension. It should be noted that in the case of BOSB joint, the self-drilling screws were bent (due to the yield of the screws) and the shavings near them were pulled out, resulting in the failure of the joint. But in the case of WOSB joint, the board cracked and large pieces were pulled out (the board is damaged). This was also the reason that obvious peak appeared in the displacement-force curve of Fig. 5b, c. 


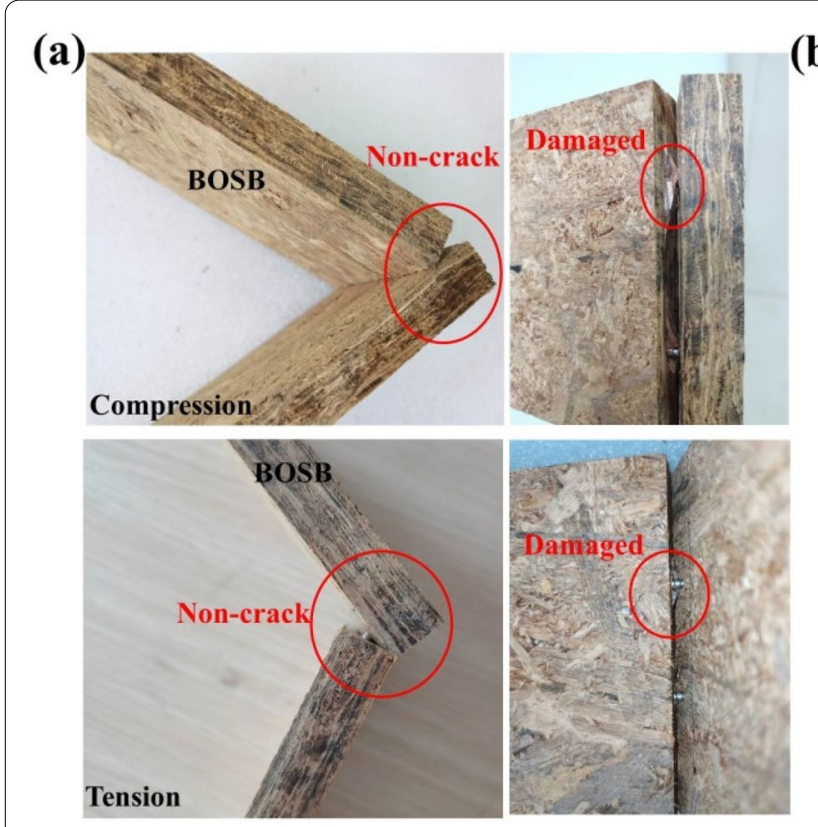

(b)
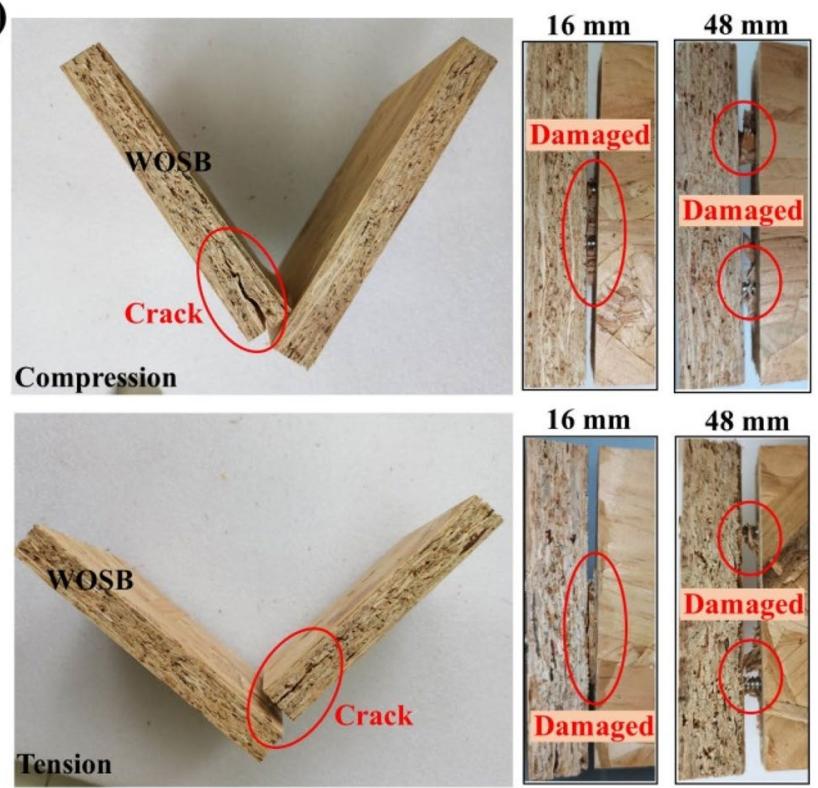

$48 \mathrm{~mm}$

Fig. 6 Typical damage of joints: a BOSB, b WOSB

An important and reliable indicator of joint strength was provided by the maximum bending moment. Figure 7 shows the effect of screw spacing on the bending moment. It could be seen from Fig. 7a that in the tensile test, it was clear from this figure that in the tensile test, the bending moment of BOSB joint with screw spacing of $16 \mathrm{~mm}\left(M_{\mathrm{T}}=69.97 \mathrm{~N} \mathrm{~m}\right)$ was $38 \%$ higher than that of BOSB joint with screw spacing of $16 \mathrm{~mm}\left(M_{\mathrm{T}}=50.80 \mathrm{~N}\right.$ $\mathrm{m})$. It indicated that screw spacing significantly affected the strength of BOSB joint [28]. In contrast, screw spacing has little effect on WOSB joint.
The bending moment of joints subjected to tensile was greater than that of compression joints. For BOSB joint, the $M_{\mathrm{T}}$ was about 1.5 times $M_{\mathrm{C}}$, and the $M_{\mathrm{T}}$ was about 2 times $M_{\mathrm{C}}$ for WOSB joint. The $M_{\mathrm{C}}$ of the BOSB joint was almost 3.5- to 4-fold higher than that of the WOSB joint. It can be seen from Fig. $7 \mathrm{~b}$ that the bending moment of the BOSB joint in the compressive test increased and then decreased with the increase of screw spacing, and the maximum bending moment at the screw spacing of $48 \mathrm{~mm}\left(M_{\mathrm{C}}=47.4 \mathrm{~N} \mathrm{~m}\right)$ was $23 \%$ higher than the smallest bending moment at the screw spacing of
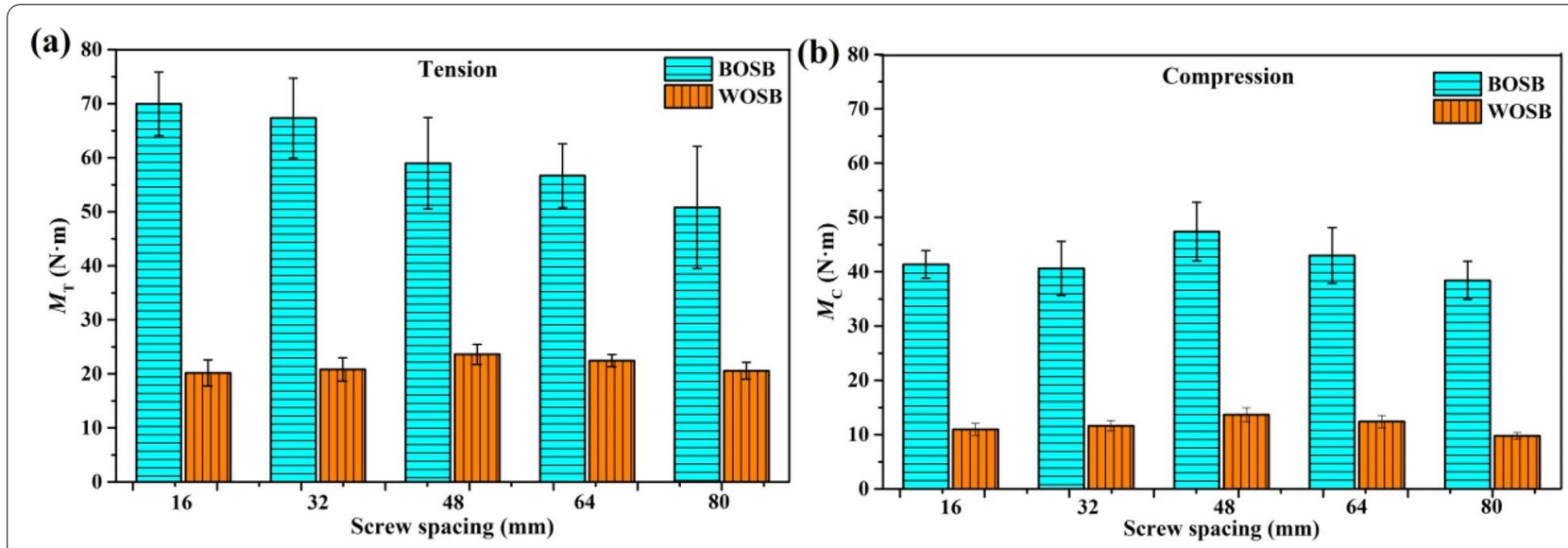

Fig. 7 Bending moment of joints at: a tension, $\mathbf{b}$ compression 
$80 \mathrm{~mm}\left(M_{\mathrm{C}}=38.39 \mathrm{~N} \mathrm{~m}\right)$. However, for WOSB joints, the highest bending moment at the screw spacing of $48 \mathrm{~mm}\left(M_{\mathrm{C}}=13.65 \mathrm{~N} \mathrm{~m}\right)$ was $40 \%$ higher than the smallest bending moment at the screw spacing of $80 \mathrm{~mm}$ $\left(M_{\mathrm{C}}=9.78 \mathrm{~N} \mathrm{~m}\right)$, which indicated that the screw spacing had much more obvious effect on the bending moment of WOSB joints during compression test.

Analysis of variance (Tables 2 and 3) revealed a significant difference between the bending moments for joints connected with different screws spacing. For the tension test, $F(\mathrm{BOSB})=7.652>F(\mathrm{WOSB})=4.785$, thus screw spacing affected the bending moment of BOSB joint more than that of WOSB. While, for the compression test, $F(\mathrm{BOSB})=4.573<F(\mathrm{WOSB})=15.780$, which indicated screw spacing affected the bending moment of WOSB joint more than that of BOSB.

Summing up it may be generalized that the screw spacing was $48 \mathrm{~mm}$, the BOSB joints had the largest bending moment for compressive and the smallest difference with the tensile bending moment, so this screw spacing was beneficial to improve the safety of furniture structure [37]. In this case, the WOSB joint also has better strength. Moreover, when Moreover, the strength of joint with screw-fixed joint was greater compared to two-inone and three-in-one [19].

\section{Joint stiffness}

Stiffness of joints was evaluated based on the change of stiffness coefficient $K(\mathrm{~N} \mathrm{~m} / \mathrm{rad})$ in the function of rotation angle $\Delta \phi(\mathrm{rad})$. Analyses of results given in Fig. 8 indicated that the $\Delta \phi-K$ curves were smooth, and stiffness coefficient $K$ increased with the increase of rotation angle $\Delta \phi$ nonlinearly before reaching the maximum value. In the tension test curve, the peak width of BOSB joints was greater than that of WOSB joints, which indicated that BOSB joints had better durability. The curves also showed that the stiffness coefficient of the BOSB joints was greater than that of the WOSB joints. Additionally, the stiffness coefficient curves showed that in the compression test joints obtain maximum stiffness coefficient at an almost twofold greater than that of subjected to tension. Besides, when the stiffness coefficient reaches the maximum, the $D P$ of the BOSB joint in the case of the compression and tensile tests were around $7.7 \mathrm{~mm}$ and $5.5 \mathrm{~mm}$, respectively, and it greater than that of WOSB. It confirms that the BOSB joint has better durability.

Figure 9 shows the effect of the screw spacing on the stiffness coefficient. It could be seen from Fig. 9a that the stiffness coefficient of BOSB joint decreased with the increase of screw spacing, while it increased for WOSB joint in tension test. In the compression test, the stiffness coefficient of the BOSB and WOSB joint tended to increase and then decrease with increasing spacing, their stiffness coefficient reaches the maximum when the screw spacing was $48 \mathrm{~mm}$. Compared with the difference in bending moment, the difference in stiffness coefficient between WOSB and BOSB joint was slightly smaller. For BOSB joints with screw spacing of $48 \mathrm{~mm}$ the stiffness coefficient takes values of $K_{\mathrm{T}}=324.54 \mathrm{Nm} / \mathrm{rad}$ in the case of tension and

Table 2 ANOVA results of tension moment of joints

\begin{tabular}{|c|c|c|c|c|c|c|}
\hline Material & Source of variation & Sum of squares & $d f$ & Mean square & $F$ & $\begin{array}{l}\text { Level of } \\
\text { significance }\end{array}$ \\
\hline \multirow[t]{3}{*}{ BOSB } & Between groups & 1976.597 & 4 & 494.149 & 7.652 & 0.000 \\
\hline & Within groups & 2260.235 & 35 & 64.578 & & \\
\hline & Total & 4236.832 & 39 & & & \\
\hline \multirow[t]{3}{*}{ WOSB } & Between groups & 67.405 & 4 & 16.851 & 4.785 & 0.003 \\
\hline & Within groups & 123.268 & 35 & 3.522 & & \\
\hline & Total & 190.672 & 39 & & & \\
\hline
\end{tabular}

Table 3 ANOVA results of compression moment of joints

\begin{tabular}{|c|c|c|c|c|c|c|}
\hline Material & Source of variation & Sum of squares & $d f$ & Mean square & $F$ & $\begin{array}{l}\text { Level of } \\
\text { significance }\end{array}$ \\
\hline \multirow[t]{3}{*}{$\mathrm{BOSB}$} & Between groups & 362.825 & 4 & 90.706 & 4.573 & 0.004 \\
\hline & Within groups & 694.189 & 35 & 19.834 & & \\
\hline & Total & 1057.014 & 39 & & & \\
\hline \multirow[t]{3}{*}{ WOSB } & Between groups & 68.437 & 4 & 17.109 & 15.780 & 0.000 \\
\hline & Within groups & 37.947 & 35 & 1.084 & & \\
\hline & Total & 106.384 & 39 & & & \\
\hline
\end{tabular}



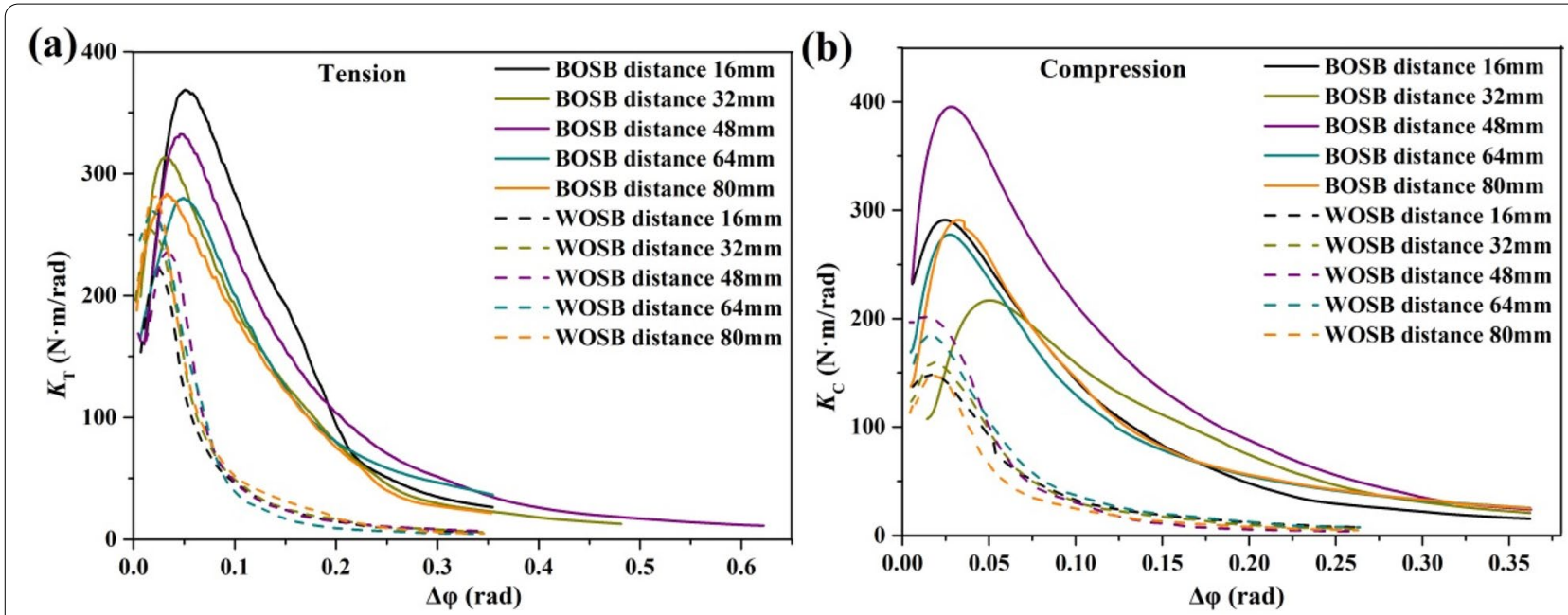

Fig. 8 Variation of stiffness coefficient $K(\mathrm{~N} \cdot \mathrm{m} / \mathrm{rad})$ in the function of the rotation angle $\Delta \varphi$ (rad) of joint: a compression, $\mathbf{b}$ tension
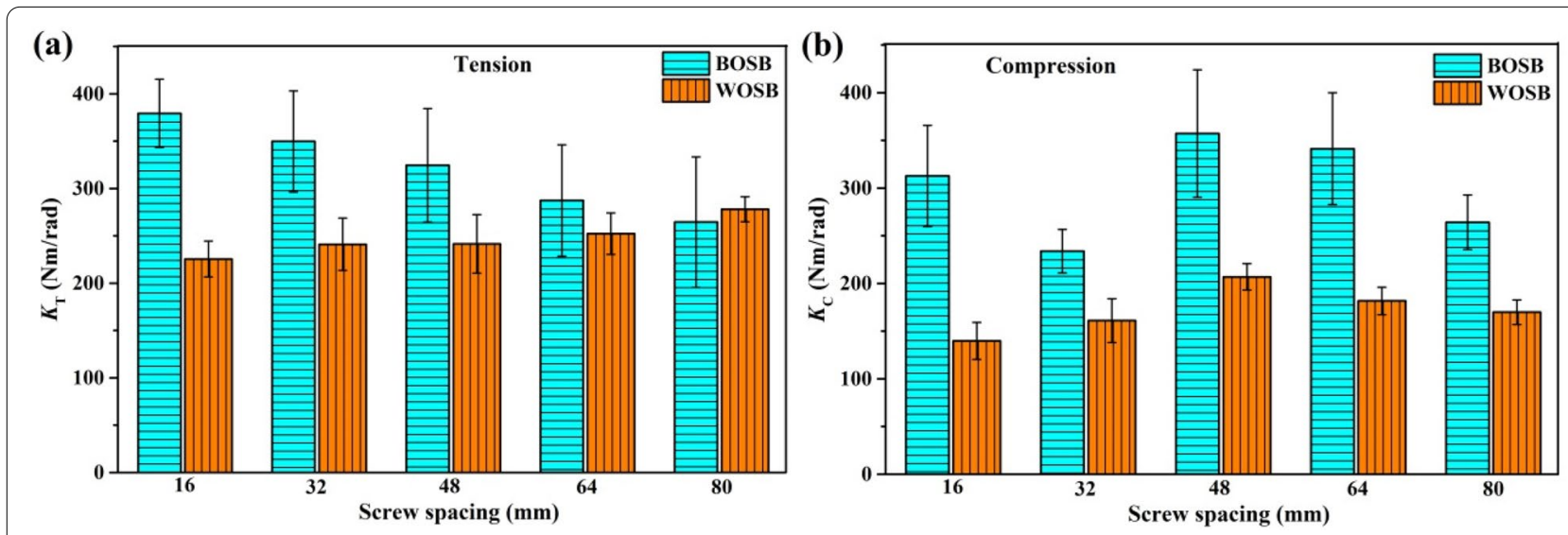

Fig. 9 Stiffness coefficient for joints subjected to: a tension, $\mathbf{b}$ compression

$K_{\mathrm{C}}=357.06 \mathrm{Nm} / \mathrm{rad}$ for compression, which differs by as little as $9 \%$. This showed that the loading mode has less influence on the stiffness coefficient of BOSB joints with screw spacing of $48 \mathrm{~mm}$. In the tension test the stiffness coefficient of BOSB joints with screw spacing of $32 \mathrm{~mm}, K_{\mathrm{T}}=349.68 \mathrm{Nm} / \mathrm{rad}$, was slightly greater than that of the joint in compression test was minimum at $K_{\mathrm{C}}=233.78 \mathrm{Nm} / \mathrm{rad}$. Thus the difference of $33 \%$ was significant. The difference of stiffness coefficient of BOSB joint with screw spacing of $16 \mathrm{~mm}$ between in tension and compression test was $18 \%$. To the structural design of frame furniture, such a trend was highly disadvantageous. This was connected with the commonly observed type of deformation, e.g., in the side plating of bedsteads. In this case, joints were subjected alternately to tension and compression [15]. Thus, the BOSB joint with screw spacing of $48 \mathrm{~mm}$ has a comparable or identical stiffness to ensure high structural reliability. The results of ANOVA results show the screw spacing had significant influence on the stiffness coefficient of both BOSB and WOSB joint, and it affected the tensile stiffness more than compression stiffness.

\section{Results of numerical calculations for modeled joints}

Figure 10 presents the Von Mises stresses of joints subjected to compression. From Fig. 10, we can observe that the highest stresses were concentrated in bottom of holes. It meant that with the load increases, the first damage occurred in this part of the plate [29]. The developing stresses were caused by the pressure of the self-drilling screws on the side surface of the hole. The boards on the inside of the joint also had large stresses due to compression. The results showed that the place with higher stress was the most vulnerable to failure, which was confirmed by the failure mode in the experimental test. And it also 


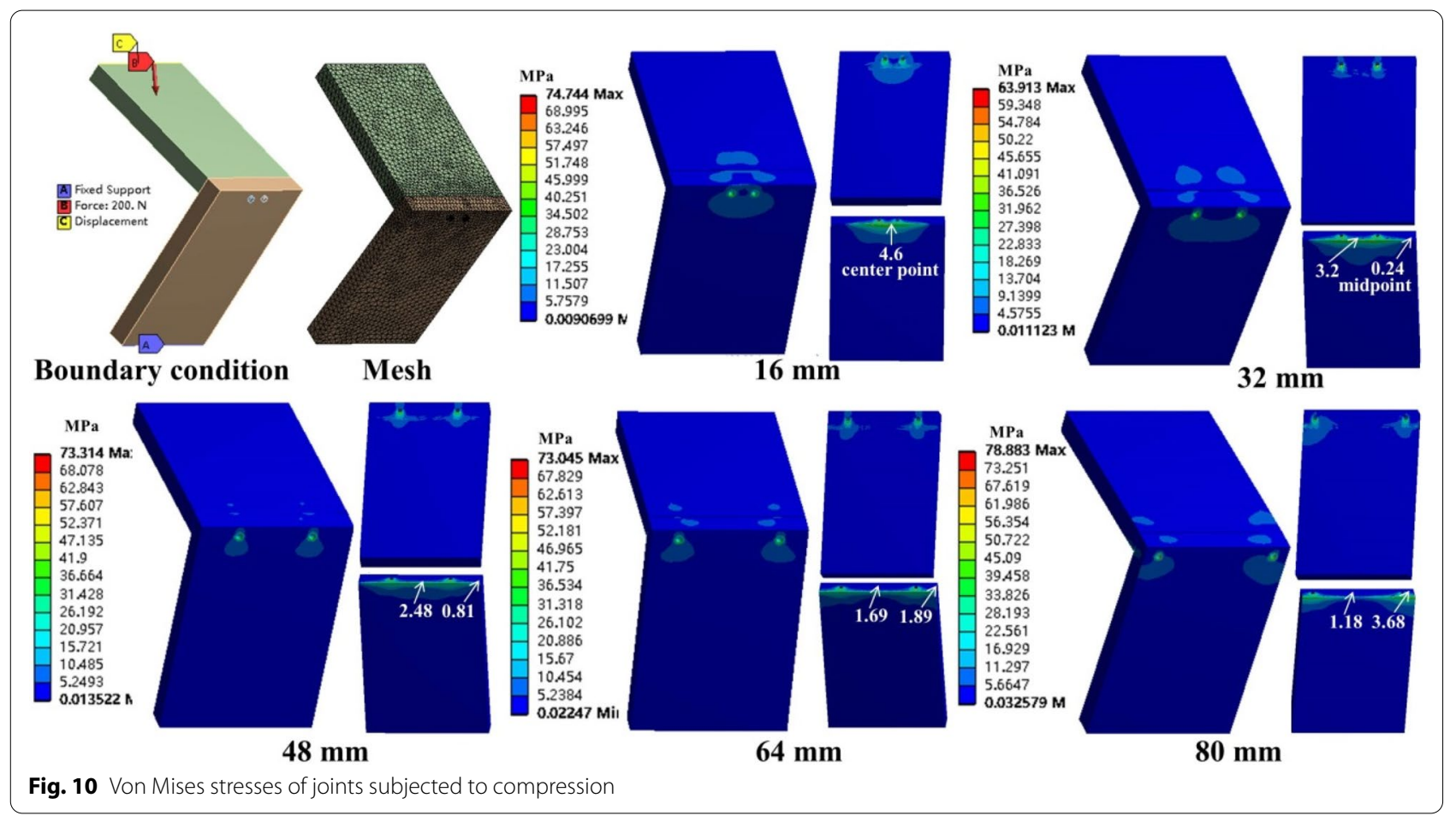

showed the validity of the numerical analysis results. Moreover, it was found from Fig. 10 that under the same force, the stress distribution on the BOSB joints with screw spacing of 48 and $64 \mathrm{~mm}$ was significantly smaller than that with screw spacing of 16,32 and $80 \mathrm{~mm}$. This indicated that the safety of BOSB joints with screw spacing of 48 and $64 \mathrm{~mm}$ were higher than that of BOSB joints with other screw spacing, which was also verified by the experimental data.

Figure 11 presents the Von Mises stresses of joints subjected to tension. The maximum stress was also concentrated near the hole on the inside of the screw bend. For boards parallel to the screw installation direction, the leverage on the screw causes the boards to delaminate and crack. Typical damages of arms illustrated in Fig. 6 caused by joint compression or tension corresponded with the results of numerical calculations indicating the same places of failure. Comparing the Von Mises stresses of different joints in Fig. 11, it was found that the maximum stress of joints with screw spacing of 48 and $64 \mathrm{~mm}$ was smaller, which indicates that the joints were safer. This result corresponds to the experimental result.

\section{Conclusions}

In this study, the effect of screw spacing on corner joint stiffness and strength of BOSB was studied using FEM and experimental test to optimize self-drilling screw spacing compared with WOSB. The following conclusions were drawn:

(1) The bending moment and stiffness coefficient were significantly affected by screw spacing. The screw spacing affected the mechanical property of BOSB joints more significantly than that of WOSB joints in tension test, while for compression test the screw spacing affected the bending moment and stiffness coefficient of WOSB joints more significantly than that of BOSB joints. The bending moment of BOSB joints subjected to compression and tension were almost 3.5- to 4-fold greater than that of WOSB joints, while the difference of stiffness coefficient was small. Moreover, the bending moment of BOSB joints subjected to tension was almost twofold greater than compressed samples.

(2) For BOSB, the screw spacing of $48 \mathrm{~mm}$ could ensure the maximum strength and stiffness of corner joints and improve the safety of furniture.

(3) The failure of BOSB joints was caused by the screw yielding and pulling out from the board (noncracking). Due to the small mechanical strength of WOSB, the boards cracked during joint bending, resulting in the failure of the corner joints. 


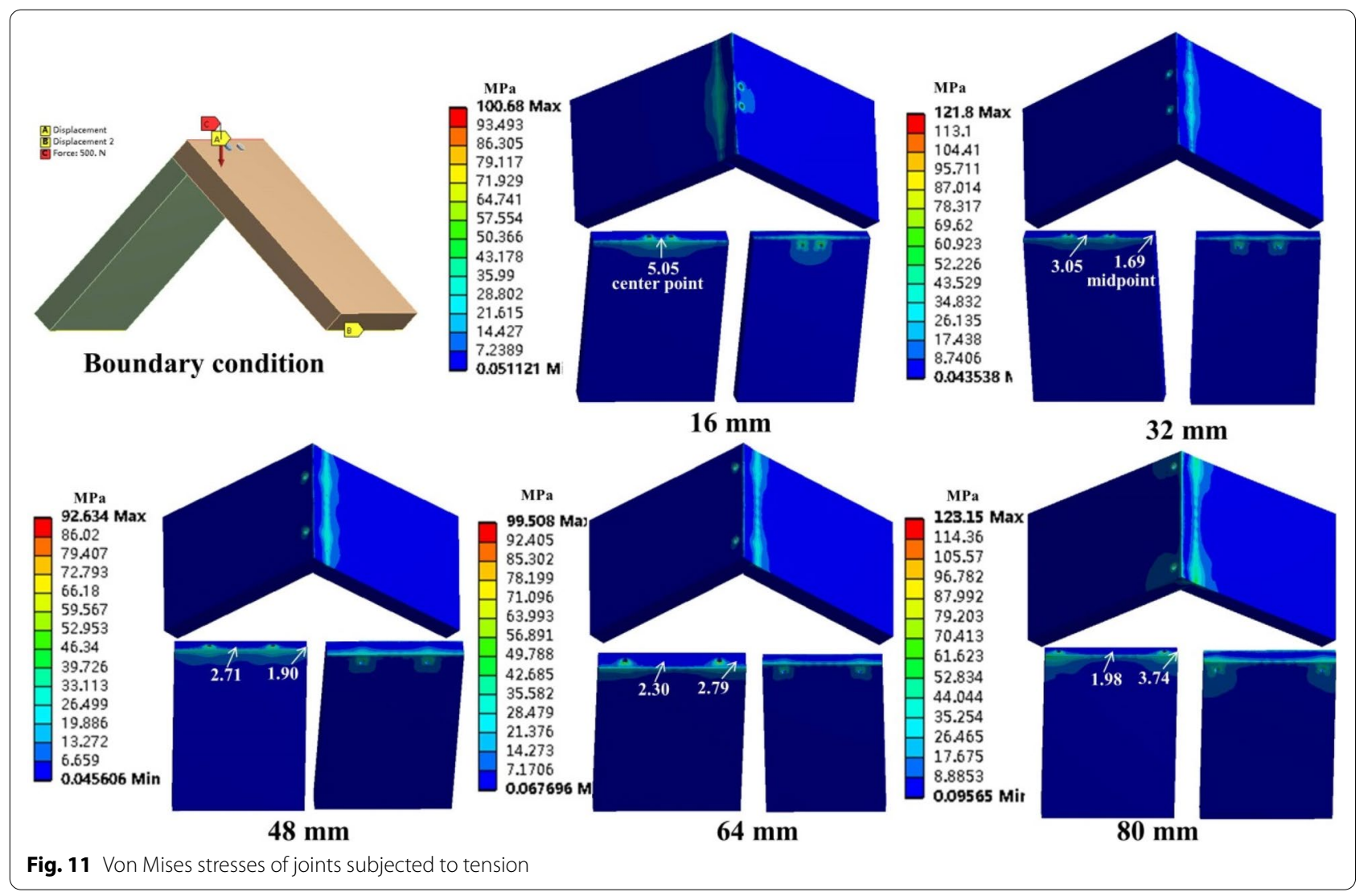

(4) A comparison of displacement and failure mode of joints between experiment test and FEM showed that their results were the same and confirm the finite element analysis was effective.

\section{Abbreviations}

BOSB: Bamboo-oriented strand board; FEM: Finite element method; WOSB: Wood-oriented strand board; PB: Particleboard; MDF: Medium-density fiberboard; HDF: High-density fiberboard.

\section{Acknowledgements}

The authors would like to thank the anonymous reviewers and editor for their valuable comments and suggestions for improving the quality of this paper.

\section{Authors' contributions}

Conceptualization, SL, YC, and YG; data curation, KZ, XF, CL, and YB; formal analysis, $K Z$, and $R X$; funding acquisition, $Y C, S L$, and $Y G$; investigation, $K Z$ and $\mathrm{XF}$; methodology, $\mathrm{KZ}$ and FW; resources, $\mathrm{YC}$ and $\mathrm{YG}$; supervision, $\mathrm{YC}$ and $\mathrm{YG}$; validation, YC, SL, and YG; writing —original draft preparation, KZ; writing review and editing, KZ and FW; funding acquisition, YC, SL, and YG. All authors read and approved the final manuscript.

\section{Funding}

The authors would like to express their heartfelt gratitude to the National Science and Technology Major Project of China (2016 YFD 0600905), China Natural Science Foundation (3180047) and the National Key Research and Development Program (2017YFD0600201).
Availability of data and materials

Not applicable.

\section{Declarations}

Ethics approval and consent to participate

Not applicable.

\section{Consent for publication}

Not applicable.

\section{Competing interests}

The authors declare that they have no competing interests.

Received: 17 May 2021 Accepted: 19 November 2021

Published online: 15 December 2021

\section{References}

1. Biswas D, Bose SK, Hossain MM (2011) Physical and mechanical properties of urea formaldehyde-bonded particleboard made from bamboo waste. Int J Adhes Adhes 31(2):84-87

2. Fu Y, Fang H, Dai F (2017) Study on the properties of the recombinant bamboo by finite element method. Compos Part B-Eng 115:151-159. https://doi.org/10.1016/j.compositesb.2016.10.022

3. Bahari SA, Grigsby WJ, Krause A (2017) Thermal stability of processed PVC/bamboo blends: effect of compounding procedures. Eur J Wood Wood Prod 75(2):147-159. https://doi.org/10.1007/s00107-016-1148-5 
4. Akinlabi ET, Anane-Fenin K, Akwada DR (2017) Bamboo Taxonomy and Distribution Across the Globe. Bamboo. https://doi.org/10.1007/ 978-3-319-56808-9_1

5. Febrianto F, Jang JH, Lee SH, Santosa IA, Kim NH (2015) Effect of Bamboo Species and Resin Content on Properties of Oriented Strand Board Prepared from Steam-treated Bamboo Strands. BioResources 10(2):26422655. https://doi.org/10.15376/biores.10.2.2642-2655

6. Febrianto F, Sahroni HW, Bakar ES, Kwon GJ, Kwon JH, Kwon J (2012) Properties of oriented strand board made from Betung bamboo (Dendrocalamus asper (Schultesf) Backer ex Heyne). Wood Sci Technol 46(1-3):53-62. https://doi.org/10.1007/s00226-010-0385-8

7. Apriani MT, Febrianto F, Karlinasari L (2012) Physical and Mechanical Properties of Bamboo Oriented Strand Board Made from Steamed Pretreated Bamboo Strands under Various Bamboo Species and Resin Content. Bogor, Institute Pertanian Bogor

8. Chaowana P (2013) Bamboo: an alternative raw material for wood and wood-based composites. J Mater Sci Res 2(2):90-102. https://doi.org/10. 5539/jmsr.v2n2p90

9. Wan-Si FU, Huang J (2007) A Study on Manufacturing Technology for Bamboo OSB with PF Resin. China Wood Indus 21(2):7-9

10. Zhang H, Du, (2007) Research and development of production technology of bamboo waferboard and oriented strand board based on biological characteristics and timber adaptability. J Bamboo Res 26(2):43-48

11. Sumardi I, Suzuki S (2013) Parameters of Strand Alignment Distribution Analysis and Bamboo Strandboard Properties. BioResources 8(3):44594467. https://doi.org/10.15376/biores.8.3.4459-4467

12. Bakar ES, Nazip M, Anokye R, Hua LS (2019) Comparison of three processing methods for laminated bamboo timber production. J Forestry Res 30(2):363-369. https://doi.org/10.1007/s11676-018-0629-2

13. Kasal A, Yuksel M, Fathollahzadeh A, Ziya Y, Yildirim EN (2011) Ultimate failure load and stiffness of screw jointed furniture cabinets constructed of particleboard and medium-density fiberboard. Forest Prod J 61(2):155160. https://doi.org/10.13073/0015-7473-61.2.155

14. Ratnasingam J, loras F (2013) Effect of adhesive type and glue-line thickness on the fatigue strength of mortise and tenon furniture joints. Eur J Wood Wood Prod 71(6):819-821. https://doi.org/10.1007/ s00107-013-0724-1

15. Smardzewski J, Imirzi HO, Lange J, Podskarbi M (2015) Assessment method of bench joints made of wood-based composites. Compos Struct 123(5):123-131. https://doi.org/10.1016/j.compstruct.2014.12.039

16. Feng W (2009) The Application of FEM in Furniture Construction Design. China Forest Prod Ind 36(4):41-43

17. Sun Y, Jiang Z, Zhang X, Sun Z, Liu H (2019) Behavior of glued laminated bamboo and bamboo-oriented strand board sheathing-to-framing connections. Eur J Wood Wood Prod 77(6):1189-1199. https://doi.org/10. 1007/s00107-019-01454-3

18. Liu XS, Liu XJ, Ji-Qing LI (2017) The test and analysis of nail holding power about recombinant bamboo used in furniture. Wood Process Mach 28(5):10-12

19. Xu R, Zhang K, Ren L, Wang F, Chen Y (2021) Connection Performance Examination of a New Bamboo-Oriented Strand Board Connector. BioResources 16(2):2906-2920. https://doi.org/10.15376/biores.16.2.2906-2920

20. Kukun T, Smardzewski J, Kasal A (2020) Experimental and numerical analysis of mounting force of auxetic dowels for furniture joints. Eng Struct 226(1):111351. https://doi.org/10.1016/j.engstruct.2020.111351

21. Guo Y, Zhu S, Chen Y (2018) Contrastive analysis of screw withdrawal resistance between bamboo oriented strand board and conventional particleboard. Wood Res 63(6):1071-1080
22. Sapiee SF, Lau HH (2013) Influence of screw spacing on the strength of self-drilling screw connection for the high strength cold-formed steel. Adv Mat Res 712-715(1):1054-1057. https://doi.org/10.4028/www.scien tific.net/AMR.712-715.1054

23. Roy K, Lau HH, Ting TCH, Masood R, Lim JBP (2019) Experiments and finite element modelling of screw pattern of self-drilling screw connections for high strength cold-formed steel. Thin Wall Struct 145:106393. https://doi. org/10.1016/j.tws.2019.106393

24. Zhang J, Eckelman CA (1993) Rational design of multi-dowel corner joints in case construction. Forest Prod J 43(11):52-58. https://doi.org/10.1080/ 02773819408003114

25. Hao J, Xu L, Wu X, Li X (2020) Analysis and modeling of the dowel connection in wood T type joint for optimal performance. Compos Struct 253:112754. https://doi.org/10.1016/j.compstruct.2020.112754

26. Kasal A, Erdil YZ, Zhang J, Efe H, Avci E (2008) Estimation equations for moment resistances of L-type screw corner joints in case goods furniture. Forest Prod J 58(9):21-27. https://doi.org/10.1007/s10342-008-0227-5

27. Hu W, Liu N (2020) Numerical and optimal study on bending moment capacity and stiffness of mortise-and-tenon joint for wood products. Forests 11(5):501. https://doi.org/10.3390/f11050501

28. Smardzewski J, Lewandowski W, Imirzi HÖ (2014) Elasticity modulus of cabinet furniture joints. Mater Design 60:260-266. https://doi.org/10. 1016/j.matdes.2014.03.066

29. Smardzewski J, Slonina M, Maslej M (2017) Stiffness and failure behaviour of wood based honeycomb sandwich corner joints in different climates. Compos Struct 168(5):153-163. https://doi.org/10.1016/j.compstruct. 2017.02.047

30. ASTM D2395-14 (2011) Standard Test Methods for Density and Specific Gravity (Relative Density) of Wood and Wood-Based Materials. ASTM International: West Conshohocken.

31. ASTM D4442-07 (2012) Standard test methods for direct moisture content measurement of wood and wood-base materials. ASTM International: West Conshohocken

32. Koc KH, Kizilkaya EES, Korkut DS (2011) The use of finite element method in the furniture industry. Afr J Bus Manage 5(3):855-865. https://doi.org/ 10.1626/pps.9.83

33. Krzyaniak U, Smardzewski J (2019) Strength and stiffness of new designed externally invisible and demountable joints for furniture cases. Eng Struct 199:109674. https://doi.org/10.1016/j.engstruct.2019.109674

34. Podskarbi M, Smardzewski J (2019) Numerical modelling of new demountable fasteners for frame furniture. Eng Struct 185(15):221-229. https://doi.org/10.1016/j.engstruct.2019.01.135

35. ASTM D3039/D3039M-17 (2017) Standard Test Method for Tensile Properties of Polymer Matrix Composite Materials. ASTM International: West Conshohocken

36. LY/T 3219 (2020) Self-tapping screws for timber structures. The state forestry administration of the People's Rep: Standards press of china

37. Smardzewski J (2009) The reliability of joints and cabinet furniture. Wood Res 54(1):67-76. https://doi.org/10.1145/1553374.1553534

\section{Publisher's Note}

Springer Nature remains neutral with regard to jurisdictional claims in published maps and institutional affiliations.

\section{Submit your manuscript to a SpringerOpen ${ }^{\circ}$ journal and benefit from:}

- Convenient online submission

- Rigorous peer review

- Open access: articles freely available online

- High visibility within the field

Retaining the copyright to your article

Submit your next manuscript at springeropen.com 